\title{
Assessing the performance of fruit colour based phenotypes of tall (Typica) coconuts (Cocos nucifera $\mathbf{L}$.) in Sri Lanka
}

\author{
S. A. C. N. Perera ${ }^{1 *}$, W.M.Kumarasinghe ${ }^{2}$, and T.M.C.P.Gunasekara ${ }^{2}$ \\ ${ }^{I}$ Genetics and Plant Breeding Division, Coconut Research Institute, Lunuwila, 61150, Sri Lanka. \\ ${ }^{2}$ Faculty of Agriculture and Plantation Management, Wayamba University of Sri Lanka, Makandura, Gonawila. \\ *Corresponding author: S.A.C.N. Perera, E mail: chandrikaperera2003@yahoo.com
}

\begin{abstract}
Sri Lanka tall (variety Typica, form typica) is the most widely cultivated coconut form in Sri Lanka. Sri Lanka tall coconuts display variation in fruit colour ranging from green to divergent brownish red (rathi). The growers' perception is that rathi seedlings are more vigorous and higher yielding than the green phenotype. A study was conducted to evaluate and compare the nut and copra yield and seedling vigour of phenotypic groups of green, rathi and intermediate coloured fruits. Secondary data for nut yield recorded over 21 years and husked nut weight of 30 nuts per palm collected over a year in 30 palms in each of the three phenotypes were used for analysis. Furthermore, primary data for seedling girth, height and leaf number in 30 palms each of rathi and green phenotypes were collected for analysis. The data was subjected to Analysis of variance using MINITAB 16. Nut yield or the husked nut weight of the three phenotypes was not significantly different. Significant differences were observed in seedling collar girth between rathi and green phenotypes, with rathi seedlings appearing more vigorous as indicated by the thicker stem compared to the green seedlings. It is concluded that, there are no differences in the nut and copra yield among different colour forms of Sri Lanka Tall coconuts while the rathi seedlings appear superior due to their thicker seedling girth.
\end{abstract}

KEY WORDS: Coconut (Cocos nucifera L.) Sri Lanka Tall , Fruit colour, Nut yield

\section{INTRODUCTION}

Tall coconut variety Typica is the most commonly grown commercial coconuts in the world. The first coconut classification in Sri Lanka (Liyanage, 1958) includes eight morphologically distinct tall coconut forms; namely Sri Lanka Tall (Typica), Ran thembili,
Gon thembili, Porapol, Bodiri, Kamandala, Navasi and Dikiri. Of these, the Sri Lanka Tall (SLT) coconut form constitutes the mainstay of coconut cultivation in Sri Lanka occupying the majority of coconut stands in the country (Liyanage et al. 1988). SLT coconuts are hardy and widely adapted and therefore are cultivated in all the coconut growing regions in the country. 
The tall coconuts usually are the types selected for commercial planting because of their general superiority in copra production both in quality and quantity (Everard, 2004). SLT palms grown commercially live productively for about 60 years giving a yield around 7400 9880 nuts $\backslash$ ha year depending on the age, soil, climate and management after reaching yield stability at 16-18 years (Liyanage, 1955).

SLT coconuts are naturally cross pollinating and therefore consist of heterozygous individuals and heterogenous populations resulting in a vast diversity among the individual palms. One such major variation is in the colour of the fruit epicarp, which ranges from green through shades of olive to reddish brown with green being the predominant fruit epicarp colour (Liyanage, 1958). The three discrete phenotypic groups based on the epicarp have been; named "green" "intermediate" and "rathi"/brown. The general perception of the coconut growers is that the phenotype "rathi" is superior to green phenotype in nut production and general vigour of the palm. As a result there is a higher demand for "rathi" seedlings in comparison to green seedlings, at the nursery. Therefore, the current study was conducted with the objective of determining whether there are differences in nut yield, fruit component, dehusked nut weight and the vigour of seedlings among the three phenotypes green, intermediate and rathi.

\section{MATERIALS AND METHODS}

\section{Sample palms}

The data gathered from ninety adult palms comprising thirty palms each of green, rathi and intermediate fruit colour based coconut phenotypes (Fig 1) planted at field No. 04 of the Isolated Coconut Seed Garden at Ambakelle were used for this study. Colour based discrete groups were selected considering clear variations and leaving out shades varying from each group to the next. The selected palms were all of the same age and were under similar management practices.

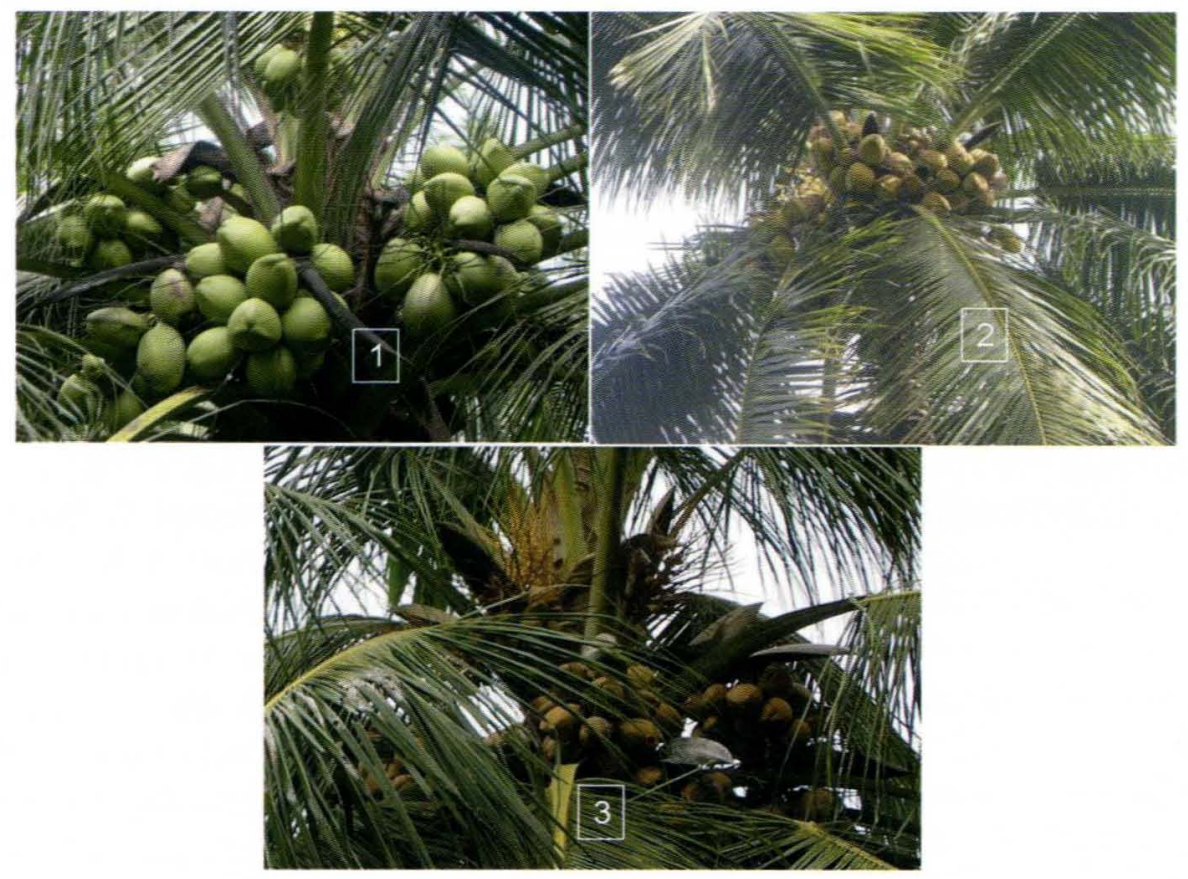

Fig. 1: Green (1), Intermediate (2) and Rathi (3) phenotypes of Sri Lanka Tall coconuts 


\section{Nut yield and husked nut weight components}

Annual nut production of each palm recorded over a period of 21 years, from 1975 to 1986 and 1992 to 2000 were used to analyze the nut yield. The fruit component, dehusked nut weight, recorded as the average of five nuts per palm per pick and scored over six picks at bi-monthly intervals in 1977 was also obtained for analysis.

\section{Seedling traits}

A total of 60 seedlings aged 5 months from the date of seed laying and representing 30 palms each from green and rathi phenotypes were selected for measuring the seedling traits height, stem girth and the number of leaves. The phenotypes of green and rathi are easily identifiable at the seedling stage based on the colour of the stem and the leaf petiole. However, the intermediate group is not so easily discernible which may result in the misclassification and therefore, the intermediate group was omitted from the analysis of seedling traits.

\section{Data analysis}

Analysis of Variance was performed on the data using the statistical software MINITAB, to determine the difference among the three phenotypes.

\section{RESULTS AND DISCUSSION}

\section{Nut yield}

The analysis of variance for annual nut yield per palm during the considered period did not reveal any statistically significant difference among the three phenotypes (Fig 2) indicating the equal potential of the different phenotypes for coconut yield.

\section{Mean annual nut yield of green, intermediate and rathi phenotypes}

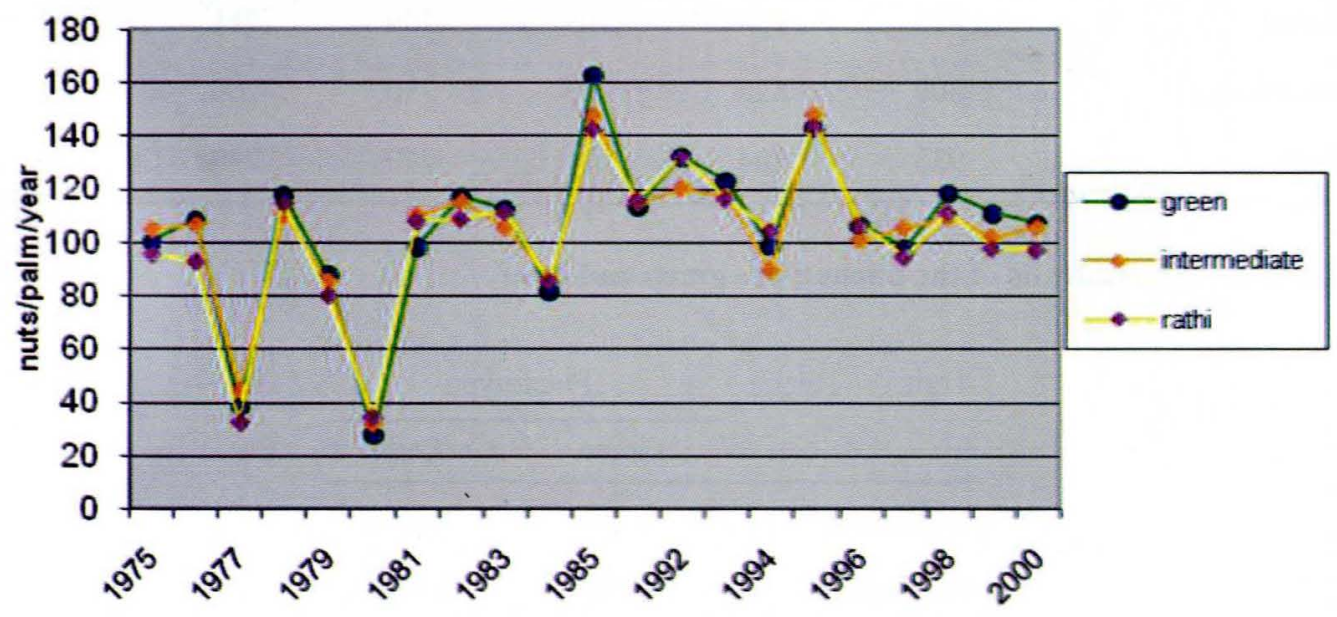

Figure 2: Mean annual coconut yield of green, intermediate and rathi phenotypes 


\section{Husked nut weight}

Husked nut weight is the most important fruit component in relation to copra production. The analysis of husked nut weight of the 3 phenotypes did not reveal any statistically significant differences among the three phenotypes (Table 01). This indicated that the nuts of all the three phenotypes were similar in their capacity for copra production.

Means in each column are not significantly different

\section{Seedling traits}

Girth of the seedling at base was significantly higher in rathi than green. Number of leaves and the height of the seedling although greater in rathi were not significantly different between the two phenotypes (Table 2). Larger girth is one of the most important parameters in determining the vigour of a seedling (unpublished data/ CRI). Therefore rathi seedlings appear to be more vigorous and this may be a reason for the preference of growers for rathi seedlings at the nursery.

The palms used for recording nut yield and husked nut weight are located at Isolated Seed Garden, Ambakelle which is a very favourable location for coconut. The current analysis for yield can be applied to the relevant phenotypes grown in similar environments where there are favourable conditions for coconut growing. However, the findings of the current analysis may not be extended to predict the performance of the three coconut phenotypes when grown in marginal environments.

Table 01: Average husked nut weights (in grams) of green, intermediate and rathi in six picks of the year

\begin{tabular}{lcccccc}
\hline Phenotype & Pick1 & Pick2 & Pick3 & Pick4 & Pick5 & Pick6 \\
\hline Green & 822 & 754 & 709 & 709 & 711 & 652 \\
Intermediate & 809 & 822 & 725 & 730 & 706 & 656 \\
Rathi & 935 & 804 & 741 & 790 & 740 & 656 \\
\hline
\end{tabular}

Table 2: Nursery traits of the phenotypes green and rathi

\begin{tabular}{lcc}
\hline Trait & \multicolumn{2}{c}{ Phenotype } \\
\cline { 2 - 3 } & Green & Rathi \\
\hline Girth $(\mathrm{cm})^{*}$ & $9.93 \mathrm{a}$ & $10.67 \mathrm{~b}$ \\
Height $(\mathrm{cm})$ & $104.30 \mathrm{a}$ & $112.03 \mathrm{a}$ \\
No. of leaves & $4.5 \mathrm{a}$ & $4.8 \mathrm{a}$ \\
\hline
\end{tabular}




\section{CONCLUSIONS}

There is no significant difference among the green, intermediate and rathi phenotypes of Sri Lanka tall coconuts in terms of nut production when grown in suitable soils for coconut. The three coconut phenotypes of SLT do not differ in their capacity for copra production. Rathi seedlings showed larger girth at the base than the green seedlings implying that the former is more vigorous than the green seedlings.

\section{ACKNOWLEDGEMENTS}

The authors acknowledge the assistance from Dr.Lalith Perera, Miss.Auchithya Dissanayaka, Mr.G.K.Ekanayake, and Mr.S.A.S. Chandrasiri of the Genetics and Plant Breeding Division of the Coconut Research Institute of Sri Lanka.

\section{REFERENCES}

Everard J.M.D.T. (2004). From Ceylon latin square to coconut genome frame work: A Relentless journey. In: Proceedings of the international conference of the coconut Research Institute of Sri Lanka - part 1) (Eds: T.S.G. Peiris and C. S. Ranasinghe). The Coconut Research Institute of Sri Lanka, Lunuwila 61150, Sri Lanka. 11-18.

Liyanage D.V. (1955). Planting materials for coconut. Ceylon Coconut Quarterly. 6: 75-80.

Liyanage D.V. (1958). Varieties and forms of the coconut palm grown in Ceylon. Ceylon Coconut Quarterly. 9: 1-10.

Liyanage D.V., Wickramaratne M.R.T. and Jayasekera C. (1988). Coconut breeding in Sri Lanka. Cocos 6: 1-26. 